\title{
Gamma Knife radiosurgery for the management of cerebral metastases from non-small cell lung cancer
}

\author{
Greg Bowden, MD, MSc, ${ }^{1,3,5}$ Hideyuki Kano, MD, PhD, ${ }^{1,3}$ Ellen Caparosa, BS, ${ }^{4}$ \\ Seong-Hyun Park, MD, PhD, ${ }^{1,3}$ Ajay Niranjan, MCH, MBA, ${ }^{1,3}$ John Flickinger, MD, ${ }^{2,3}$ \\ and L. Dade Lunsford, MD ${ }^{1,3}$
}

\begin{abstract}
Departments of ${ }^{1}$ Neurological Surgery and ${ }^{2}$ Radiation Oncology, and ${ }^{3}$ Center for Image-Guided Neurosurgery, ${ }^{4}$ University of Pittsburgh School of Medicine, Pittsburgh, Pennsylvania; and ${ }^{5}$ Department of Neurological Surgery, University of Western Ontario, London, Ontario, Canada
\end{abstract}

\begin{abstract}
OBJECT Non-small cell lung cancer (NSCLC) is the most frequent cancer that metastasizes to brain. Stereotactic radiosurgery (SRS) has become the management of choice for most patients with such metastatic tumors. Therefore, the authors endeavored to elucidate the survival and SRS outcomes for patients with NSCLC metastasis at their center.
\end{abstract}

METHODS In this single-institution retrospective analysis, the authors reviewed their experience with NSCLC metastasis during a 10-year period from 2001 to 2010. Seven hundred twenty patients underwent Gamma Knife radiosurgery. A total of 1004 SRS procedures were performed, and 3143 tumors were treated. The NSCLC subtype was adenocarcinoma in 386 patients, squamous cell carcinoma in 111 patients, and large cell carcinoma in 34 patients. The median aggregate tumor volume was $4.5 \mathrm{~cm}^{3}$ (range $0.1-88 \mathrm{~cm}^{3}$ ).

RESULTS The median survival time after diagnosis of brain metastasis from NSCLC was 12.6 months, and the median survival after SRS was 8.5 months. The 1-, 2-, and 5-year survival rates after SRS were $39 \%, 21 \%$, and $10 \%$, respectively. Postradiosurgery survival was decreased in patients treated with prior whole-brain radiation therapy compared with SRS alone $(p=0.003)$. Aggregate tumor volume was inversely related to survival after SRS $(p<0.001)$, and the histological subgroups demonstrated significant survival differences $(p=0.023)$. The overall local tumor control rate in the entire group was $92.8 \%$. One hundred seventy-four patients (24\%) underwent repeat SRS for new or resistant metastatic deposits.

CONCLUSIONS Stereotactic radiosurgery is an effective means of providing local control for NSCLC metastases. Neurological function and survival benefit from serial patient monitoring and repeat SRS for new tumors.

http://thejns.org/doi/abs/10.3171/2014.12.JNS141111

KEY WORDS non-small cell lung cancer; lung cancer; metastasis; stereotactic radiosurgery; Gamma Knife; brain; oncology

$\mathrm{L}$ UNG cancer is the most common malignancy in the world, accounting for $13 \%$ of all documented cancer cases, of which $85 \%$ are non-small cell lung cancer (NSCLC). NSCLC is often diagnosed at an advanced stage, as $56 \%$ of patients present with distant metastases. ${ }^{31}$ The 5-year survival for NSCLC is $19.3 \%$ overall but decreases to $4.1 \%$ with distant metastases. ${ }^{15}$

Intracranial metastases occur in an estimated 30\%$40 \%$ of patients with NSCLC and are often identifiable at the time of primary diagnosis. ${ }^{6,18,23}$ The presence of intracranial metastases is invariably associated with a decrease in median survival across all cancer types. ${ }^{10}$ The median survival for a patient with NSCLC and intracranial metastases who forgoes treatment is reportedly less than 2 months. The addition of fractionated whole-brain radiation therapy (WBRT) increases survival to only 3-6 months. ${ }^{4,6}$

Gamma Knife radiosurgery (GKRS) has proven to be a low risk and effective treatment strategy for a wide variety of patients with brain metastases. The local tumor control after SRS in NSCLC patients consistently exceeds $80 \%$ in the literature. ${ }^{24,30}$ The utilization of SRS for NSCLC metastases has increased significantly and appropriately

ABBREVIATIONS GKRS = Gamma Knife radiosurgery; KPS = Karnofsky Performance Scale; NSCLC = non-small cell lung cancer; RPA = recursive partitioning analysis; RTOG = Radiation Therapy Oncology Group; SRS = stereotactic radiosurgery; WBRT = whole-brain radiotherapy.

SUBMITTED May 18, 2014. ACCEPTED December 2, 2014.

INCLUDE WHEN CITING Published online February 6, 2015; DOI: 10.3171/2014.12.JNS141111.

DISCLOSURE Dr. Lunsford is a consultant for and owns stock in AB Elekta, Stockholm, Sweden. 
since the turn of the century. ${ }^{13}$ In this study, we present the imaging and survival outcomes of patients who underwent GKRS for intracranial metastases from NCSLC at a single institution.

\section{Methods}

\section{Patient Characteristics}

A single-institution retrospective analysis approved by the University of Pittsburgh institutional review board was conducted. This study evaluated survival outcomes in patients who underwent GKRS over a 10-year period between January 1, 2001, and December 31, 2010. During this time a total of 720 patients underwent SRS for intracranial NSCLC brain metastases. A total of 1004 SRS procedures (including retreatment for new disease), were conducted for the management of 3143 tumors. The outcome data were collected through medical record review and were analyzed retrospectively by neurosurgeons unaffiliated with the initial patient management. The median patient age was 63 years (range 27-96 years) at the time of SRS. Three hundred sixty-nine patients were men (51\%). The histological NSCLC origin was adenocarcinoma in 386 patients (54\%), squamous cell carcinoma in 111 patients (15\%), and large cell carcinoma in 34 patients $(5 \%)$ (Table 1). NSCLC was confirmed in an additional 189 patients $(26 \%)$ pathologically, but a subtype remained unclear or unidentified.

There was a median interval of 1.5 months between primary diagnosis and presentation with intracranial metastases. Two hundred eighty-one patients (39\%) had a synchronous diagnosis. Four hundred forty-nine patients (62\%) presented with multiple metastases (range 2-23), and 271 patients $(38 \%)$ presented with a solitary metastasis. Active systemic disease was present in 549 patients (76\%) and extracranial metastases were identified in 271 patients (31\%) at the time of SRS. Prior to SRS, 85 patients $(12 \%)$ had undergone a craniotomy for gross-total resection of at least 1 tumor and 373 patients $(52 \%)$ had received WBRT. In response to their systemic disease, 486 patients (68\%) had received systemic chemotherapy and 227 patients (32\%) had received both WBRT and chemotherapy. The median pretreatment Karnofsky Performance Scale (KPS) score was 90 (range 30-100). ${ }^{36}$ Stratification by recursive partitioning analysis (RPA) devised by the Radiation Therapy Oncology Group (RTOG) showed Class 1 in 61 patients (8\%), Class 2 in 647 patients (90\%), and Class 3 in 12 patients $(2 \%) \cdot{ }^{10,11}$

\section{Radiosurgery Technique}

The expanded technical elements of this procedure have been detailed in our previous publications..$^{14,22}$ Briefly, SRS was conducted as an outpatient procedure and intravenous conscious sedation was used. The Leksell stereotactic frame was applied after a local anesthetic agent was administered to the pin sites. High-resolution axial imaging (MRI unless contraindicated) was then conducted. Radiosurgery planning was calculated using a 3D conformal plan enveloping the entire enhancing tumor volume. This study spans the use of Leksell Gamma Knife models C, $4 \mathrm{C}$, and Perfexion (Elekta AB).

Clinical and imaging follow-up were requested at
TABLE 1. Summary of demographic and tumor characteristics

\begin{tabular}{|c|c|}
\hline Variable & Value $^{*}$ \\
\hline No. of patients & 720 \\
\hline \multicolumn{2}{|l|}{ Age (yrs) } \\
\hline Median & 63 \\
\hline Range & $27-96$ \\
\hline \multicolumn{2}{|l|}{ Sex } \\
\hline Male & $369(51)$ \\
\hline Female & $351(49)$ \\
\hline \multicolumn{2}{|l|}{ NSCLC subtype } \\
\hline Adenocarcinoma & $386(54)$ \\
\hline Squamous cell & $111(15)$ \\
\hline Large cell & $34(5)$ \\
\hline Undetermined & $186(26)$ \\
\hline \multicolumn{2}{|l|}{ Metastases } \\
\hline Solitary & $271(38)$ \\
\hline Multiple & $449(62)$ \\
\hline Primary active & $549(76)$ \\
\hline Extracranial metastases & $271(31)$ \\
\hline \multicolumn{2}{|l|}{ KPS score } \\
\hline Median & 90 \\
\hline Range & $30-100$ \\
\hline No. w/ score $\geq 90$ & $536(74)$ \\
\hline Prior WBRT & $373(52)$ \\
\hline Prior surgery & $85(12)$ \\
\hline Prior chemotherapy & $486(68)$ \\
\hline \multicolumn{2}{|l|}{ RPA class } \\
\hline 1 & $61(8)$ \\
\hline 2 & $647(90)$ \\
\hline 3 & $12(2)$ \\
\hline
\end{tabular}

* Values are presented as the number patients (\%) unless indicated otherwise.

3-month intervals after SRS. If the intracranial disease burden increased as a result of new metastases or tumor growth, a repeat SRS procedure was recommended. The median aggregate target volume was $4.5 \mathrm{~cm}^{3}$ (range $0.1-$ $88 \mathrm{~cm}^{3}$ ), and the largest single metastatic deposit volume was $3.25 \mathrm{~cm}^{3}$ (range $\left.0.1-78 \mathrm{~cm}^{3}\right)$. A median of 2 metastases (range 1-19) were treated at each radiosurgical procedure. The median marginal dose was 18 Gy (range 10-22 Gy) and the maximum dose was 34 Gy (range 20-50 Gy).

Factors influencing dose selection included but were not limited to: tumor characteristics (volume, number, and location) and previous radiation procedures. In general, the minimal margin dose for each tumor was 18-20 Gy. Dose reduction (e.g., $16 \mathrm{~Gy}$ ) was used in select patients in whom WBRT had failed within the last 12 months. Margin doses were prescribed at various isodoses that ranged from $50 \%$ to $80 \%$ depending on the tumor volume. The use of higher margin doses, as suggested by RTOG guidelines, was not employed in this series since tumor control response as well as reduction in complication risks were achieved using the doses described above. This paradigm is based on our experience in excess of 4000 patients with various metastatic histological subtypes. 
Repeat radiosurgery was conducted 284 times in 174 patients. After the procedure, all patients received 20-40 $\mathrm{mg}$ of intravenous methylprednisolone. Patients were discharged from the hospital within 2-24 hours after the procedure. If any changes in neurological symptoms occurred after treatment, the patient was evaluated with imaging to assess for potential adverse radiation effects.

\section{Statistical Analysis}

Kaplan-Meier analysis was used to demonstrate correlations and for graphic interpretations of survival rates based on significant factors. Cox regression was used for univariate and multivariate analyses to calculate significant interactions between survival rates and related factors. A $p$ value $<0.05$ was defined as statistically significant. Comparisons between variable groups were performed where appropriate using the Fisher exact test. Variables analyzed in relation to survival included age, sex, KPS score, tumor (volume, number, and subtype) extracranial metastasis, primary status, margin dose, WBRT, resection and chemotherapy, and RPA.

\section{Results}

\section{Survival}

At study completion, 658 patients (91\%) had died and 62 patients $(9 \%)$ were alive. The median survival after NSCLC diagnosis was 19.9 months (range 1-178 months). Survival rates at 1,2, and 5 years are based on KaplanMeier estimates. The 1-year survival after diagnosis was $70 \%$, and at 5 years it was $16 \%$. There was an increase in survival from diagnosis in patients with a controlled primary tumor $(p<0.001)$, younger age $(p=0.008)$, and female sex $(p=0.008)$. The time from diagnosis of NSCLC until the diagnosis of brain metastases was prolonged by systemic chemotherapy treatment $(\mathrm{p}=0.009)$. The median survival from the diagnosis of brain metastasis was 12.6 months (range 1-175 months). Statistically, this represented $52 \%$ survival at 1 year, $26 \%$ at 2 years, and $12 \%$ at 5 years. The median survival after SRS was 8.5 months (0.5-158 months). This corresponded to a 6-month survival of $61 \%$, 1-year survival of 39\%, 2-year survival of $21 \%$, and 5 -year survival of $10 \%$.

Survival time from SRS decreased as age increased ( $\mathrm{p}$ $<0.001$ ). The median survival was 11.2 months for age $<60$ years and 7.1 months for age $\geq 60$ years. Survival was increased for female patients and the presence of a controlled primary tumor $(\mathrm{p}=0.011$ and $\mathrm{p}<0.001$, respectively). A higher KPS score at SRS correlated with an increased survival time ( $\mathrm{p}<0.001)$. A KPS score $\geq$ 90 was associated with a median survival of 9.5 months compared with 5.2 months for KPS score < 90 . A median tumor margin dose $>18$ Gy increased survival $(p=0.006)$. Patients who required multiple SRS procedures had improved survival $(\mathrm{p}<0.001)$. RPA analysis delineated median survivals after SRS of 14 months in Class 1, 8 months in Class 2, and 2 months in Class 3 ( $\mathrm{p}<0.001$ ) (Fig. 1).

Survival between histological subtypes differed significantly. The median survival from SRS for patients with adenocarcinoma was 10.5 months compared with those with squamous cell carcinoma, which was 5.2 months (p
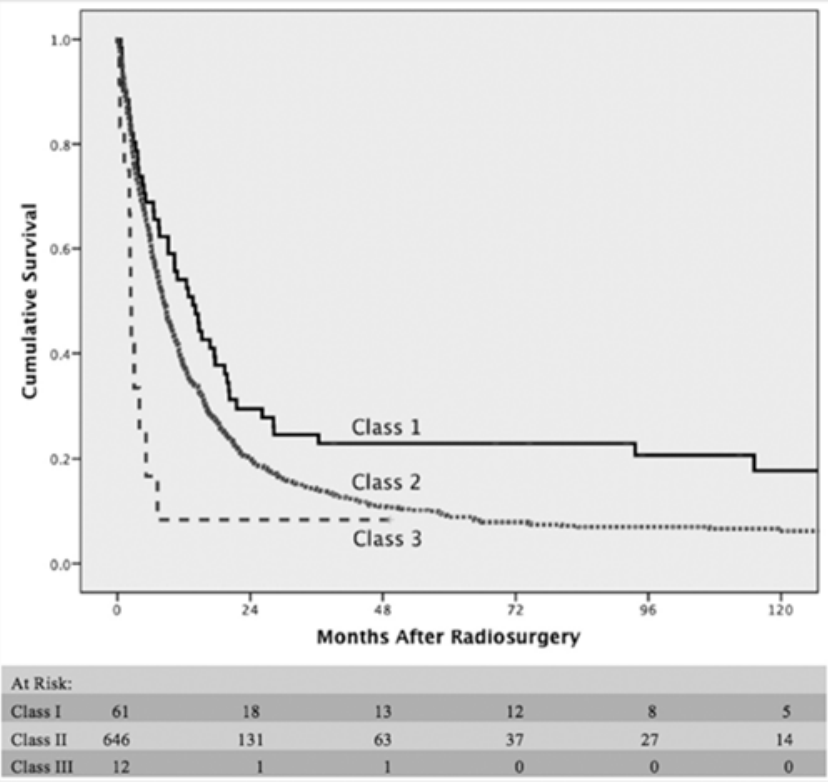

FIG. 1. Kaplan-Meier curve depicting survival from SRS based on the RPA scale. The median survival for Classes I, II, and III were 13.6 months, 8.3 months, and 2.3 months respectively $(p<0.001)$. The patients remaining in the equations are depicted at each time point. Graph truncated to 10 years.

$=0.023)$ (Fig. 2). The large cell subtype was consistent with survival of patients with adenocarcinoma (median survival of 10 months). Survival after metastasis diagnosis and after SRS decreased as the aggregate tumor volume increased ( $\mathrm{p}=0.001$ and $\mathrm{p}<0.001$, respectively). A median survival of 10.3 months was associated with an aggregate tumor volume $<5 \mathrm{~cm}^{3}$ compared with a median survival of 6.4 months for patients whose total tumor volume was $\geq 5 \mathrm{~cm}^{3}$ (Fig. 3). The volume of the largest

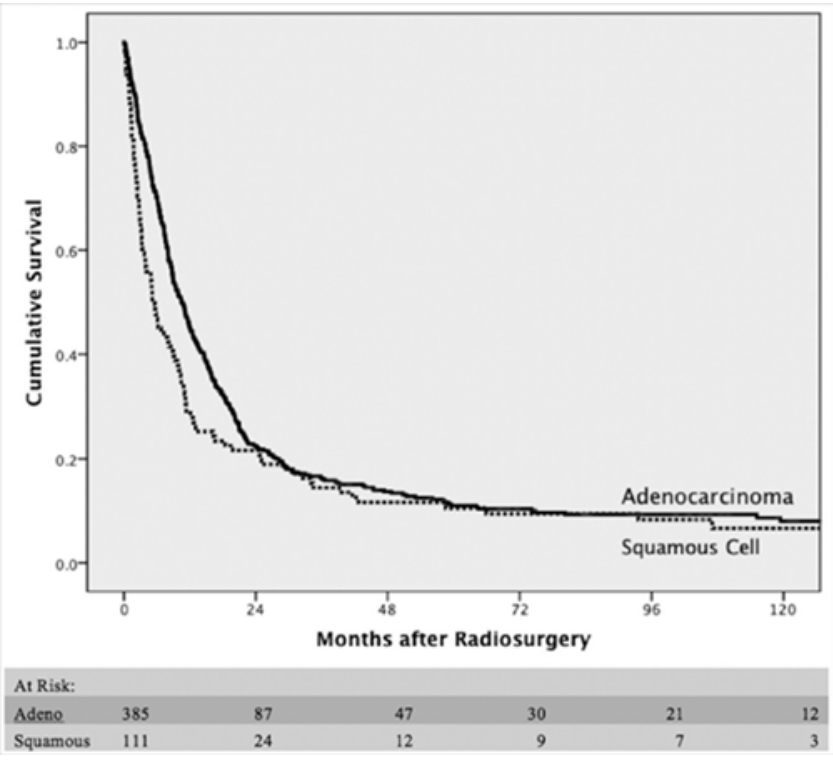

FIG. 2. Kaplan-Meier curve depicting survival from SRS in patients based on tumor subtype $(p=0.023)$ (large cell line not shown). The patients remaining in the equations are depicted at each time point. Graph truncated to 10 years. adeno $=$ adenocarcinoma. 

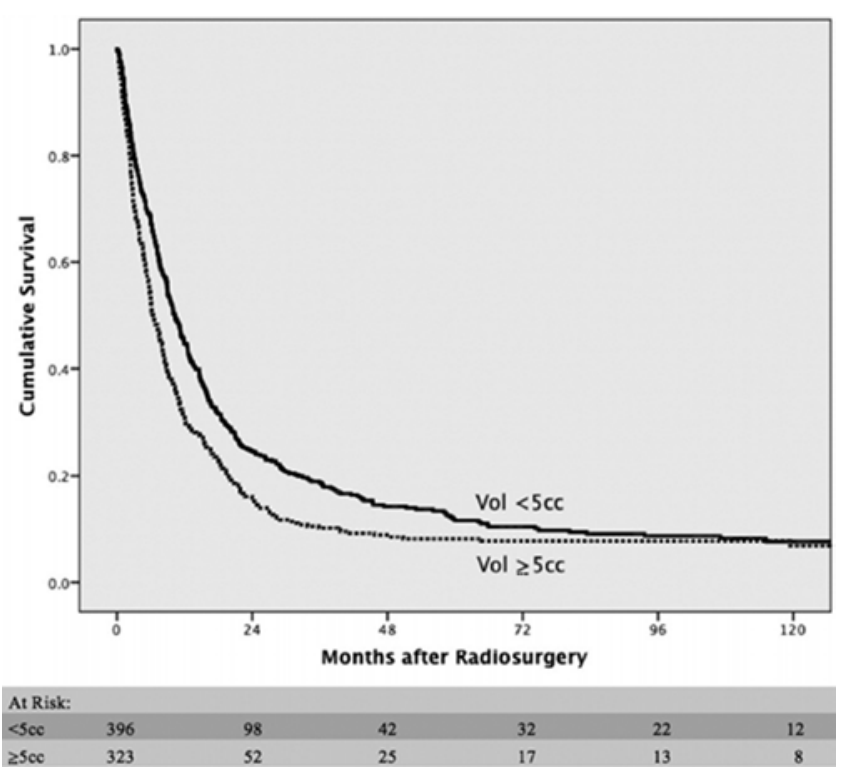

FIG. 3. Kaplan-Meier curve depicting survival from SRS in patients with an aggregate tumor volume $\geq 5 \mathrm{~cm}^{3}$ or $<5 \mathrm{~cm}^{3}(p<0.001)$. The patients remaining in the equations are depicted at each time point. Graph truncated to 10 years.

single metastatic tumor was also significant for survival after SRS $(p=0.001)$. The presence of multiple brain metastases was a negative predictor of survival $(\mathrm{p}=0.017)$. The survival from SRS based on the number of metastases was 10.3 months for a solitary lesion, 8.5 months for 2-4 metastases, and 6.1 months for $\geq 5$ metastases. The survival from initial brain metastasis diagnosis was 14.6 months for 1 metastasis, 11.6 months for 2-4 metastases, and 11.5 months for $\geq 5$ metastases (Fig. 4).

The use of prior WBRT negatively correlated with survival after SRS $(p=0.003)$. The median survival was 9.8 months in patients who had not received WBRT and 7.5 months for patients treated with prior WBRT (Fig. 5). Statistical significance was lost when WBRT was calculated based on survival from diagnosis of brain metastasis ( $\mathrm{p}=$ 0.955 ). Patients without prior WBRT underwent SRS at a median of 0.9 months after diagnosis of brain metastasis compared with 3.3 months in the WBRT-treated group. The percentage of patients receiving prior WBRT was associated with the number of metastases, as $30 \%$ of patients with a single metastasis, $53 \%$ of patients with $2-4$ metastases, and $68 \%$ of patients with $\geq 5$ metastases had already undergone WBRT. This delayed SRS in many patients, as the time from brain metastasis diagnosis to SRS was a median of 1.3 months in solitary metastases, 1.8 months in patients with 2-4 metastases, and 3 months in patients with $\geq 5$ metastases. WBRT was used more frequently in patients with multiple metastases $(\mathrm{p}<0.001)$, in patients with an active primary tumor $(\mathrm{p}=0.011)$, and in patients with larger tumor volumes $(\mathrm{p}=0.005)$.

This study investigated outcomes over 10 years. To ascertain whether any changes in referral pattern impacted the results, the initial 5 years and the final 5 years were analyzed and compared. Patients with multiple metastases were treated more frequently in the final 5 years of the study ( $p<0.001)$. The KPS score of patients at the time of
SRS was also statistically lower in the final 5 years $(\mathrm{p}<$ 0.001 ). In addition, some variables approached, but did not reach, significance. These included a higher rate of prior WBRT being used in the initial 5 years of the study ( $p$ $=0.073$ ). The median survival after SRS was 1.7 months longer in the initial 5 years ( 9.2 months) than the final 5 years $(7.5$ months $)(p=0.105)$. A similar finding was identified for survival from the time of brain metastasis diagnosis $(\mathrm{p}=0.078)$.

\section{Tumor Control}

Follow-up with imaging was available for 403 patients (56\%), with 1763 treated metastases at a median of 8 months (range 1-124 months). The local tumor control rate was $92.8 \%$ based on imaging follow-up. The 1-year product limit local control rate per metastasis treated was calculated at $93 \%$. This corresponded to local tumor recurrence developing in 80 patients (20\%). Therefore, 61 patients $(15 \%)$ had at least 1 metastasis requiring repeat SRS, or palliative management, and 19 patients $(5 \%)$ required resection due to tumor progression or refractory peritumoral edema. Post-SRS palliative WBRT was administered in 31 patients. The tumor subtype was identifiable in $79 \%$ of patients with follow-up. Local tumor control was 94\% (based on 1319 tumors) in the adenocarcinoma group, 92\% (based on 223 tumors) in the squamous cell group, and $92 \%$ (based on 139 tumors) in the large cell group. This represented local recurrence in $19 \%$ of adenocarcinoma patients, in $27 \%$ of squamous cell patients, and in $28 \%$ of large cell patients.

Distant brain metastases outside the original treatment field requiring repeat SRS occurred in $42 \%$ of patients with follow-up. Of patients with adenocarcinoma, squamous cell carcinoma, and large cell carcinoma, $51 \%, 21 \%$, and $35 \%$, respectively, had intracranial metastases. At the time of analysis 683 patients had died, $27 \%$ of whom died as result of progressive intracranial disease. This reflected a rate for neurological death of $25 \%$ for adenocarcinoma, $34 \%$ for squamous cell carcinoma, and $25 \%$ for large cell carcinoma based on subtype.

\section{Discussion}

\section{Survival}

Metastatic tumors are the most common intracranial neoplasms and are increasing in frequency, with an annual incidence of 170,000-200,000 in the United States. ${ }^{27}$ These lesions are invariably associated with a decreased survival and occur in upward of $30 \%$ of patients with NSCLC.$^{10,23}$ In this study, the median survival time after diagnosis of NSCLC metastases was 12.6 months, with a survival after SRS of 8.5 months. The 1-year survival rate after SRS was 39\% and the 5-year survival was $10 \%$. These results are consistent with previously published studies. ${ }^{24,30}$ There were multiple statistically significant factors that influenced survival, including sex, age, primary status, prior WBRT, KPS score, marginal dose, and tumor characteristics such as histology subtype, tumor volume, and number of metastases.

NSCLC provides an overarching tumor classification, but our understanding of tumor biology and genetics, and 

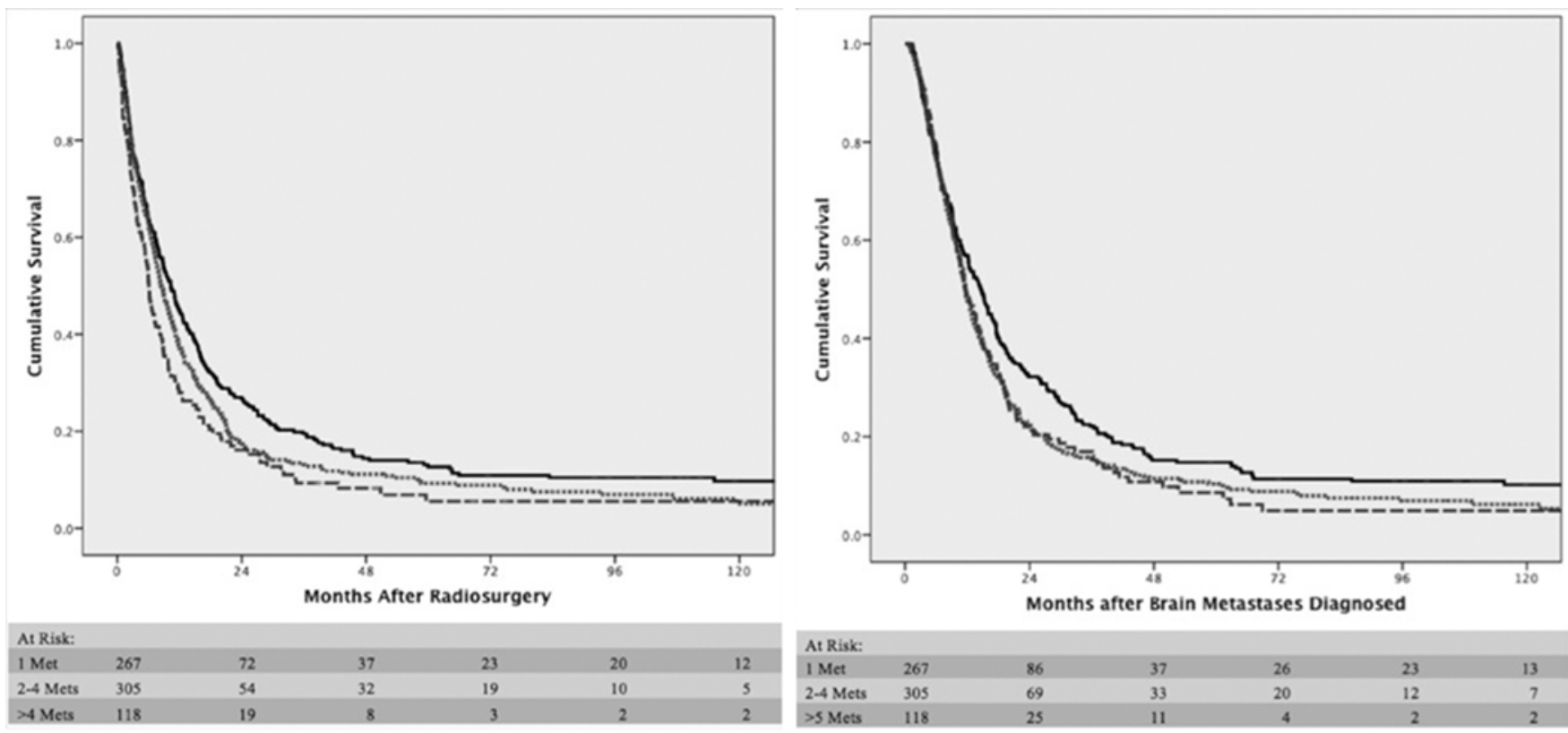

FIG. 4. Left: Kaplan-Meier curve depicting survival from SRS based on the number of metastases treated $(p=0.017)$. Right: Kaplan-Meier curve depicting survival from intracranial metastasis diagnosis based on the number of metastases treated (solid line, solitary metastasis; dotted line, 2-4 metastases; dashed line, $\geq 5$ metastases). The patients remaining in the equations are depicted at each time point. Graph truncated to 10 years.

even clinical analysis, indicates that each histological subtype is a distinct entity. The standard NSCLC histological breakdown is adenocarcinoma in $48 \%$ of patients, squamous cell in $25 \%$, large cell in $3 \%$, and other in $24 \% .^{15}$ The frequency of brain metastases in patients with adenocarcinoma and large cell carcinoma is reported to be higher than that for squamous cell carcinoma. ${ }^{6}$ This is reflected in our study as $54 \%$ of our patients had adenocarcinoma, $15 \%$ had squamous cell carcinoma, and 5\% had large cell carcinoma. Furthermore, distant metastases occurred far more frequently in the adenocarcinoma group. The tumor control rate was relatively consistent across the subtypes. However, survival within the subtypes was significantly different as patients with adenocarcinoma and large cell carcinoma both had a median survival of 10 months, whereas those with squamous cell carcinoma had a survival of only 5 months. ${ }^{30}$ Patients with squamous cell carcinoma also had a higher rate of neurological death at $34 \%$, compared with $25 \%$ for both adenocarcinoma and large cell metastases. This is comparable to the recent report by Kuremsky et al., who reached a similar conclusion regarding the value of prognostic analysis based on tumor subtype. ${ }^{20}$

The use of WBRT and its relationship to intracranial metastastic disease has been under ever-increasing scrutiny for many cancer types. Although the palliative effects of WBRT have been well documented, the risks of cognitive decline and dementia have become more prominent as medical advances extend survival. ${ }^{8,33}$ Recent publications have indicated that WBRT has no survival benefit, no improvement in functional independence, and a negative

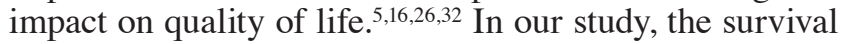
from the time of SRS was shorter by longer than 2 months in the WBRT-treated group. However, the statistical sig- nificance was neutralized when the survival from diagnosis of brain metastasis was analyzed. This can be accounted for by a time delay until SRS, since the delay was a median of 1 month for patients treated without WBRT whereas the delay was a median of 3.3 months for those treated with WBRT.

The presence of a solitary metastasis was associated with an increased survival, which is well documented in the literature. ${ }^{9,17,19}$ In regard to multiple metastases, there

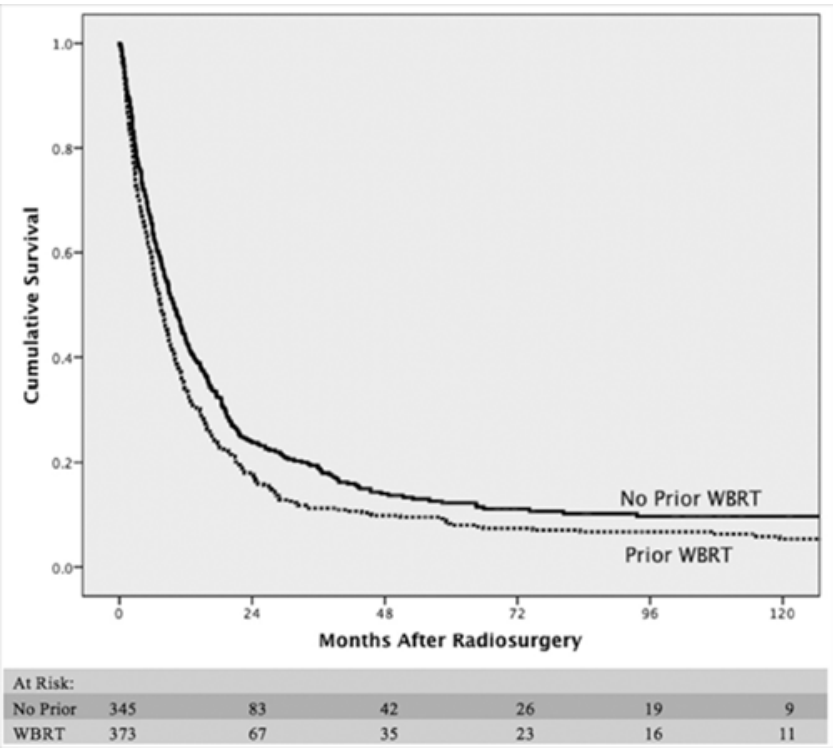

FIG. 5. Kaplan-Meier curve depicting survival from SRS based on whether patients had received WBRT treatment $(p=0.003)$. The patients remaining in the equations are depicted at each time point. Graph truncated to 10 years. 
has been a progressive increase in the number of tumors that are managed by SRS. In this study, the median survival from SRS was 10.3, 8.5, and 6.1 months for 1, 2-4, and $\geq 5$ metastases, respectively. The frequent utilization of prior WBRT in patients with multiple metastases resulted in a median time delay from intracranial metastasis diagnosis until SRS of 1.8 months for patients with 2-4 metastases and a delay of 3 months for the those with $\geq 5$ metastases. This resulted in essentially equivalent median survival from diagnosis of intracranial metastasis of 11.5 months. Yamamoto et al. and Serizawa et al. investigated patients with up to 10 metastases who did not undergo prior WBRT, which allowed for SRS to be performed within 6 weeks of diagnosis. These studies showed no statistical survival advantage between subgroups with more than 1 metastasis..$^{29,35}$ The involvement of factors such as patient age, KPS score at SRS, and RPA class appear to have a larger impact on survival predictions than the number of metastases. ${ }^{3,12,28}$

Tumor volume was a significant factor in patient survival, accounting for a 1-year survival increase of $14 \%$ after SRS. The clearest separation was demonstrated at $<5$ $\mathrm{cm}^{3}$ or $\geq 5 \mathrm{~cm}^{3}$ with an increase in median survival of 4 months. The statistical significance of tumor volume and its negative impact on overall survival has been indicated in the literature. ${ }^{2,25}$ The aggregate tumor volume was not a factor in tumor control in this paper. However, the rate of tumor control in larger metastases based on published data remains well in excess of $85 \%$ for tumors larger than $6 \mathrm{~cm}^{3} \cdot{ }^{21,26}$ In addition, a reduction in tumor volume after SRS has been documented to occur in $46 \%$ of NSCLC metastases. ${ }^{7}$ Tumor volume is known to impact neurological and cognitive functioning and is likely a more important survival factor than number of tumors.

SRS has previously demonstrated a high local control rate of brain metastases, almost independent of the cell of origin. In this study, the local tumor control rate was $92.8 \%$. The need for surgical treatment after SRS was limited in this study to less than $5 \%$ of patients, which is consistent with the analysis by Xu et al. ${ }^{34}$ Distant brain metastases requiring retreatment occurred in $42 \%$ of patients; $51 \%$ of these patients had undergone prior WBRT. Previous studies have indicated that active systemic disease results in an increased risk of distant metastases, which is consistent with our analysis.,19 This ongoing risk of new metastases supports the need for frequent clinical and imaging observation of these patients regardless of the treatment paradigm selected.

This study was truncated at 10 years with the underlying understanding that referral patterns and treatment paradigms evolve. The treatment of multiple brain metastases by SRS has increased dramatically over time, as WBRT has trended in the opposite direction. Therefore, as expected, an increased percentage of patients with multiple metastases were identified in the final 5 years of the study. A management shift is also evident in that more patients with a lower KPS score were treated in the final 5 years. The influence of the KPS score alone after SRS in the KaplanMeier curves was $>4$ months (KPS score $\geq 90$ ). Therefore, patient selection and a more aggressive approach regarding KPS score may be contributing factors to a slightly lower yet nonstatistically significant reduction in survival between the initial and final 5 years of this study.

\section{Study Limitations}

Although all patients were prospectively entered into a database at the time of SRS, this report is a retrospective review of outcomes. We acknowledge the inherent limitations of a retrospective study and the possibility of referral bias. In an attempt to offset the variations in referral patterns and treatment paradigms, such as the use of radiosurgery for treating increasing numbers of metastases, these results were analyzed and a 10-year time period was used. Some patients who had undergone WBRT were referred because of inadequate tumor response after WBRT.

\section{Conclusions}

Intracranial metastases from NSCLC are common and are associated with a poor prognosis. Aggressive management of both intracranial and systemic disease offers patients improved survival. This study demonstrates a local tumor control rate after GKRS of $92.8 \%$. The variables affecting survival were multifactorial in this analysis but included tumor volume and histological subtype. Early recognition of intracranial metastases, coupled with early SRS and repeat patient imaging to define new disease, are imperative.

\section{Acknowledgments}

We acknowledge Xiaoran Zhang, Jee-Hong Kim, Seyed H. Mousavi, and Douglas Kondziolka.

\section{References}

1. Ayala-Peacock DN, Peiffer AM, Lucas JT, Isom S, Kuremsky JG, Urbanic JJ, et al: A nomogram for predicting distant brain failure in patients treated with gamma knife stereotactic radiosurgery without whole brain radiotherapy. Neuro Oncol 16:1283-1288, 2014

2. Baschnagel AM, Meyer KD, Chen PY, Krauss DJ, Olson RE, Pieper DR, et al: Tumor volume as a predictor of survival and local control in patients with brain metastases treated with Gamma Knife surgery. J Neurosurg 119:1139-1144, 2013

3. Bhatnagar AK, Flickinger JC, Kondziolka D, Lunsford LD: Stereotactic radiosurgery for four or more intracranial metastases. Int J Radiat Oncol Biol Phys 64:898-903, 2006

4. Chang DB, Yang PC, Luh KT, Kuo SH, Hong RL, Lee LN: Late survival of non-small cell lung cancer patients with brain metastases. Influence of treatment. Chest 101:12931297, 1992

5. Chang EL, Wefel JS, Hess KR, Allen PK, Lang FF, Kornguth DG, et al: Neurocognition in patients with brain metastases treated with radiosurgery or radiosurgery plus whole-brain irradiation: a randomised controlled trial. Lancet Oncol 10:1037-1044, 2009

6. Chi A, Komaki R: Treatment of brain metastasis from lung cancer. Cancers (Basel) 2:2100-2137, 2010

7. Da Silva AN, Nagayama K, Schlesinger D, Sheehan JP: Early brain tumor metastasis reduction following Gamma Knife surgery. J Neurosurg 110:547-552, 2009

8. DeAngelis LM, Delattre JY, Posner JB: Radiation-induced dementia in patients cured of brain metastases. Neurology 39:789-796, 1989

9. Flannery TW, Suntharalingam M, Kwok Y, Koffman BH, Amin PP, Chin LS, et al: Gamma knife stereotactic radio- 
surgery for synchronous versus metachronous solitary brain metastases from non-small cell lung cancer. Lung Cancer 42:327-333, 2003

10. Gaspar L, Scott C, Rotman M, Asbell S, Phillips T, Wasserman T, et al: Recursive partitioning analysis (RPA) of prognostic factors in three Radiation Therapy Oncology Group (RTOG) brain metastases trials. Int J Radiat Oncol Biol Phys 37:745-751, 1997

11. Gaspar LE, Scott C, Murray K, Curran W: Validation of the RTOG recursive partitioning analysis (RPA) classification for brain metastases. Int J Radiat Oncol Biol Phys 47:10011006, 2000

12. Grandhi R, Kondziolka D, Panczykowski D, Monaco EA III, Kano H, Niranjan A, et al: Stereotactic radiosurgery using the Leksell Gamma Knife Perfexion unit in the management of patients with 10 or more brain metastases. J Neurosurg 117:237-245, 2012

13. Halasz LM, Weeks JC, Neville BA, Taback N, Punglia RS: Use of stereotactic radiosurgery for brain metastases from non-small cell lung cancer in the United States. Int J Radiat Oncol Biol Phys 85:e109-e116, 2013

14. Hasegawa T, Kondziolka D, Flickinger JC, Lunsford LD: Stereotactic radiosurgery for brain metastases from gastrointestinal tract cancer. Surg Neurol 60:506-515, 2003

15. Howlader N, Noone AM, Krapcho M, Garshell J, Neyman N, Altekruse SF, et al (eds): SEER Cancer Statistics Review, 1975-2010. National Cancer Institute. Bethesda, MD: National Cancer Institute, 2013 (http://seer.cancer.gov/ csr/1975_2010/) [Accessed December 4, 2014]

16. Jairam V, Chiang VL, Yu JB, Knisely JP: Role of stereotactic radiosurgery in patients with more than four brain metastases. CNS Oncol 2:181-193, 2013

17. Karlsson B, Hanssens P, Wolff R, Söderman M, Lindquist C, Beute G: Thirty years' experience with Gamma Knife surgery for metastases to the brain. J Neurosurg 111:449-457, 2009

18. Kelly K, Bunn PA Jr: Is it time to reevaluate our approach to the treatment of brain metastases in patients with non-small cell lung cancer? Lung Cancer 20:85-91, 1998

19. Kress MAS, Oermann E, Ewend MG, Hoffman RB, Chaudhry H, Collins B: Stereotactic radiosurgery for single brain metastases from non-small cell lung cancer: progression of extracranial disease correlates with distant intracranial failure. Radiat Oncol 8:64, 2013

20. Kuremsky JG, Urbanic JJ, Petty WJ, Lovato JF, Bourland JD, Tatter SB, et al: Tumor histology predicts patterns of failure and survival in patients with brain metastases from lung cancer treated with gamma knife radiosurgery. Neurosurgery 73:641-647, 2013

21. Lee CC, Yen CP, Xu Z, Schlesinger D, Sheehan J: Large intracranial metastatic tumors treated by Gamma Knife surgery: outcomes and prognostic factors. J Neurosurg 120:5259, 2014

22. Liew DN, Kano H, Kondziolka D, Mathieu D, Niranjan A, Flickinger JC, et al: Outcome predictors of Gamma Knife surgery for melanoma brain metastases. Clinical article. J Neurosurg 114:769-779, 2011

23. Linskey ME, Andrews DW, Asher AL, Burri SH, Kondziolka $\mathrm{D}$, Robinson PD, et al: The role of stereotactic radiosurgery in the management of patients with newly diagnosed brain metastases: a systematic review and evidence-based clinical practice guideline. J Neurooncol 96:45-68, 2010

24. Mariya Y, Sekizawa G, Matsuoka Y, Seki H, Sugawara T: Outcome of stereotactic radiosurgery for patients with nonsmall cell lung cancer metastatic to the brain. J Radiat Res (Tokyo) 51:333-342, 2010
25. Motta M, del Vecchio A, Attuati L, Picozzi P, Perna L, Franzin A, et al: Gamma knife radiosurgery for treatment of cerebral metastases from non-small-cell lung cancer. Int J Radiat Oncol Biol Phys 81:e463-e468, 2011

26. Pan HC, Sheehan J, Stroila M, Steiner M, Steiner L: Gamma knife surgery for brain metastases from lung cancer. J Neurosurg 102 Suppl:128-133, 2005

27. Pass HI, Carbone DP, Johnson DH, Minna JD, Scagliotti GV, Turrisi AT: Principles and Practice of Lung Cancer. Philadelphia: Lippincott Williams \& Wilkins, 2012

28. Salvetti DJ, Nagaraja TG, McNeill IT, Xu Z, Sheehan J: Gamma Knife surgery for the treatment of 5 to 15 metastases to the brain. Clinical article. J Neurosurg 118:1250-1257, 2013

29. Serizawa T, Hirai T, Nagano O, Higuchi Y, Matsuda S, Ono $\mathrm{J}$, et al: Gamma knife surgery for 1-10 brain metastases without prophylactic whole-brain radiation therapy: analysis of cases meeting the Japanese prospective multi-institute study (JLGK0901) inclusion criteria. J Neurooncol 98:163-167, 2010

30. Sheehan JP, Sun MH, Kondziolka D, Flickinger J, Lunsford LD: Radiosurgery for non-small cell lung carcinoma metastatic to the brain: long-term outcomes and prognostic factors influencing patient survival time and local tumor control. J Neurosurg 97:1276-1281, 2002

31. Siegel R, Naishadham D, Jemal A: Cancer statistics, 2012. CA Cancer J Clin 62:10-29, 2012

32. Soffietti R, Kocher M, Abacioglu UM, Villa S, Fauchon F, Baumert BG, et al: A European Organisation for Research and Treatment of Cancer phase III trial of adjuvant wholebrain radiotherapy versus observation in patients with one to three brain metastases from solid tumors after surgical resection or radiosurgery: quality-of-life results. J Clin Oncol 31:65-72, 2013

33. Tallet AV, Azria D, Barlesi F, Spano JP, Carpentier AF, Gonçalves A, et al: Neurocognitive function impairment after whole brain radiotherapy for brain metastases: actual assessment. Radiat Oncol 7:77, 2012

34. Xu Z, Elsharkawy M, Schlesinger D, Sheehan J: Gamma knife radiosurgery for resectable brain metastasis. World Neurosurg 80:351-358, 2013

35. Yamamoto M, Serizawa T, Shuto T, Akabane A, Higuchi Y, Kawagishi J, et al: Stereotactic radiosurgery for patients with multiple brain metastases (JLGK0901): a multi-institutional prospective observational study. Lancet Oncol 15:387-395, 2014

36. Yates JW, Chalmer B, McKegney FP: Evaluation of patients with advanced cancer using the Karnofsky performance status. Cancer 45:2220-2224, 1980

\section{Author Contributions}

Conception and design: Kano, Bowden. Acquisition of data: Bowden, Caparosa, Park. Analysis and interpretation of data: Bowden. Drafting the article: Kano, Bowden, Lunsford. Critically revising the article: all authors. Reviewed submitted version of manuscript: all authors. Approved the final version of the manuscript on behalf of all authors: Kano. Statistical analysis: Bowden. Study supervision: Kano.

\section{Correspondence}

Hideyuki Kano, Department of Neurological Surgery, University of Pittsburgh, Ste. B-400, UPMC Presbyterian, 200 Lothrop St., Pittsburgh,PA 15213.email: kanoh@upmc.edu. 